\title{
El ms. HC 397-573 de la Hispanic Society. algunas hipótesis de trabajo
}

\author{
The Hispanic Society's HC 397-573: Working Hypotheses
}

Daniel A Panateri

danielpanateri@conicet.gov.ar

CONICET, Argentina

Rogerio R Tostes

rtostes@uevora.pt

Centro Interdisciplinar de História, Culturas e

Sociedades - Universidade de Évora, Portugal

Recepción: 23 Abril 2021

Aprobación: 26 Julio 2021

Publicación: 01 Noviembre 2021

Cita sugerida: Panateri, D. A. y Tostes, R. R. (2021). El ms. HC 397-573 de la Hispanic Society: algunas hipótesis de trabajo. Olivar, 21(34), e102. https://doi.org/10.24215/18524478e102

\begin{abstract}
Resumen: En este trabajo intentaremos mostrar algunas características distintivas del manuscrito de la Hispanic Society (HC 397/573). La idea principal es buscar elementos que permitan entender las razones por las que dicho testimonio fue redactado. Por un lado, analizaremos el contexto políticocultural con el objeto de entender las variables espaciotemporales implicadas en la producción del manuscrito. Por otro lado, proveeremos una descripción de la tradición de Partidas y el lugar que el neoyorkino tiene en ella. Asimismo, trataremos de establecer algunas aserciones que expliquen este complejo fenómeno textual. Nos centraremos en varios conceptos tales como interporlación, refundición, y compilación con el objetivo de brindar algunas hipótesis sobre este testimonio y su condición textual.
\end{abstract}

Palabras clave: Filología, Derecho, Partidas, Castilla, Aragón.

Abstract: This paper aims to show some characteristics of the Hispanic Society's manuscript (HC 397/573). The main idea is to seek out elements that could provide a full understanding of the reason why this manuscript was written. On the one hand, we will analyze the political and cultural context in order to understand the Spatio-temporal variables involved in the production of the manuscript. On the other hand, we will provide a description of Partidas' tradition and the place that the one from New York has in it. Even more, we will try to make some assertions to explain such a complex textual phenomenon. We will focus on several concepts such as interpolation, recast, and compilation in order to give some hypotheses about this manuscript and its textual condition.

Keywords: Philology, Law, Partidas, Castile, Aragon.

\section{INTRODUCCIÓN}

El manuscrito HC 397/573 (=neoyorkino) ${ }^{1}$ resulta una composición interesante, tanto en sus aspectos codicológicos como narratológicos y textuales. Producido en el siglo XIV, seguramente durante el último tercio, dentro del entramado intelectual y burocrático de la Corona de Aragón, refleja una propuesta compositiva distinta a otros testimonios manuscritos de Siete Partidas. Este manuscrito es único por esas mismas características, lo cual hace que exceda, quizá, la calificación de híbrido que se le ha dado en 
otras oportunidades. De hecho, responde mejor a una caracterización de intervención deliberada más que a un producto azaroso de dos elementos compatibles, pero distintos. Este trabajo tiene dos propuestas centrales. Primero, contribuir al conocimiento sobre este testimonio. Por un lado, basándonos en los primeros, y escasos, pasos dados hace ya varios años, intentaremos asentar una base desde la cual partir y a la cual actualizar. Por otro lado, en el contexto del proyecto Siete Partidas Digital, nutriéndonos de miradas renovadoras y gracias al trabajo grupal que un conjunto académico de estas características permite, reorganizar la información y postular nuestras presunciones. ${ }^{2}$ Segundo, discutir en clave teórica el concepto de hibridez, entre otros, para caracterizar al neoyorkino a través de uno de sus elementos más interesantes: la presencia desmedida de interpolaciones.

Para llevar adelante este trabajo, primero plantearemos los elementos basales de la tradición manuscrita de Partidas, luego lo que se sabía y lo que sabemos del testimonio en cuestión, tanto dentro de la tradición como en sí mismo. Segundo, plantearemos un escenario contextual político-jurídico-intelectual que permita construir la base histórica de la presunción textual, filológica y codicológica de su datación y producción material. Finalmente, nos daremos a la reflexión teórica con el fin de proponer una nueva mirada sobre el testimonio.

La tradición manuscrita de las Siete Partidas es un oscuro laberinto que aún hoy nos mantiene en una profunda incertidumbre. $\mathrm{Al}$ respecto, las propuestas han sido variadas e interesantes. Cabe mencionar los principales aportes para, desde allí, arribar a alguna certeza que nos permita especular en torno no solo a cuándo, quién y dónde se produjo el neoyorkino, sino, algo que atrapa más aún nuestro interés, por qué se realizó un trabajo de tales características y, finalmente, para qué.

En referencia a la propia historia de Partidas hay cosas de las que podemos estar seguros y otras de las que no. Sabemos que Siete Partidas tuvo lugar en el siglo XIII. No sabemos si fueron promulgadas en ese siglo, lo que quiere decir que no podemos afirmarlo ni negarlo. ${ }^{3}$ Asimismo, la profusa presencia de sus manuscritos, y otros elementos semejantes, sugiere que la circulación y uso de la obra era alta. De igual modo, las noticias dadas y existencia misma de Partidas en el Ordenamiento de Alcalá (1348), así como las ediciones de Montalvo (1491) y López (1555) nos hablan de la salud y presencia de la producción alfonsí hasta la temprana modernidad, al menos. ${ }^{4}$ Sabemos que en el Ordenamiento de Alcalá, Alfonso XI promulgó Siete Partidas como derecho supletorio, dejándolas terceras en el orden de prelación, tal como indica el título 28 de dicho ordenamiento. ${ }^{5}$ Con respecto al resto de las obras jurídicas alfonsíes de mayor relevancia, hoy estamos seguros de que Espéculo es anterior a Partidas y que Setenario es posterior, donde esta última refleja una relación directa con la Primera Partida, al punto de que se ha afirmado que podría ser una reescritura de la misma (Craddock, 1986). Esta relación entre Setenario y Primera Partida es crucial para la comprensión del manuscrito neoyorkino, pero volveremos sobre ella en la última sección.

La clave de estas certezas e incertidumbres, que no exceden las propias de otras tradiciones, es la cantidad de variaciones del texto en su período redaccional y, por efecto lógico, de sus epígonos. En este sentido, ha habido diversas hipótesis más o menos aceptadas. García Gallo (1951-1952) sostuvo por primera vez las tres redacciones de la Primera Partida, las cuales se sostenían en seis familias de manuscritos, mientras que Craddock (1974 y 1981) defendió las tres redacciones sucesivas, pero circunscribiendo el abanico de variaciones a tres testimonios. Cabe destacar que estas redacciones sucesivas responderían a cambios en el proyecto jurídico-político y, según Craddock, las familias se agruparían bien hacia la naturaleza textual de Espéculo, de carácter legalista, y más temprano, o bien al de Setenario, de rasgos sapienciales y más tardío. De este modo, una primera redacción tendría lugar entre 1256 y 1265; una segunda, hasta 1274 y la tercera de 1275, momento de la muerte de Fernando de la Cerda, varón primogénito de Alfonso X, hasta 1284, momento en que muere el rey Sabio. En medio de estos años se produjeron diversos sucesos relativos a la política interna y externa que pueden sintetizarse en levantamientos, conjuras, cortes (a posteriori de dichos levantamientos) y el denominado fecho del imperio. ${ }^{6}$ Todos estos detalles son cruciales para entender 
las variaciones y la historia propia de Partidas al calor del governamiento de Alfonso sobre sus naturales. Sin embargo, baste con este panorama para comprender el escenario desde el cual observar al HS1, que es nuestro protagonista. Asimismo, conviene aclarar que el nivel de variación entre testimonios puede llegar a ser tan grande que, potencialmente, puede decirse que dos de esas tres redacciones pertenecen a dos textos completamente distintos. Esto quedó claro en el trabajo de Craddock de 1983 y, recientemente, en Panateri (2017a). La clave de la aparente conformidad con estas hipótesis, que no excluyó el debate furioso por momentos, ${ }^{7}$ es que estas dataciones se llevaron adelante observando, más que nada, los prólogos y los primeros títulos de cada obra, cuando no a través de análisis de estructura (García y García, 1963). No es este el lugar para profundizar o analizar la tradición completa. Además, sostenemos la posición asentada en Panateri (2017b) y, ciertamente, coincidimos con la propuesta de Craddock. Más allá de este mar de fondo, que aún debe ser precisado, en este trabajo se examinará un testimonio en particular que no puede ser circunscripto a ninguna de estas ramas, familias o versiones.

La condición única del neoyorkino no sobreviene por pertenecer a otra familia, sino por su condición de texto refundido. Pichel (2018) lo llama híbrido con una percepción muy atinada sobre su naturaleza textual. Esta idea se basa en considerar que el HS1 es una muestra de conciliar las dos tendencias nombradas supra: la legalista y la sapiencial. ${ }^{8}$ Ambas están contenidas en una serie de manuscritos diversos (baste citar MN0 y MN6 como los modélicos de cada versión) ${ }^{9}$. El manuscrito conservado en la Hispanic Society of America (actualmente conocida como The Hispanic. Museum \& Library) fue originalmente datado en la primera mitad del siglo XIV, evidentemente en tiempos de Alfonso XI y, particularmente, durante la década que correspondió a la elaboración del Ordenamiento de Alcalá. Así, Panateri (2018) hipotetizó que su condición única respondía a un intento del scriptorium regio por estabilizar una obra para llamarla Partidas. El trabajo posterior de Pichel (2018) contradijo esta idea y retardó la datación al último tercio o cuarto del propio siglo, con un importante énfasis en la década de 1380. Esta propuesta sobrevino por el análisis codicológico que detalló el tipo de papel (donde lo había, ya que el ms. intercala con pergamino) y, fundamentalmente, las filigranas que allí encontró y estudió. Asimismo, algo en lo que ya había coincidencia: la evidente condición $\mathrm{del} / \mathrm{de}$ los escribas que, aunque componen en castellano, las opciones elegidas, tanto gráficas como fonéticas responden a un/os hablante/s aragonés/es. Finalmente, aunque no es definitorio por obvias razones, una serie de elementos dentro del material que responden a su encuadernación sirven para denotar que se conservaba dentro de los límites de la Corona de Aragón. Este detallado trabajo permitió reconsiderar hipótesis y, en consecuencia, rearmar la línea de trabajo sobre el neoyorkino que exponemos aquí. De este modo, aunque trataremos de proveer una solución crítica al problema de la hibridez y el lugar de la interpolación en la composición textual, partiremos de estas certezas sobre el HS1, pues las compartimos y hacemos propias, para entender su contexto de producción y su propósito. Por ello, trataremos de ver el contexto probable en el cual este testimonio fue redactado para considerar su viabilidad dentro de canales oficiales y determinar su razón de existir.

¿Cuán probable es que durante el reinado de Pedro el Ceremonioso (1336-1387) se produjera este manuscrito? Es cierto que hay traducciones al catalán de Partidas, entonces, ¿por qué una versión en castellano que no responde a ningún otro testimonio conservado? ¿Por qué una versión en castellano? Esta hibridez que, insistimos, se discutirá conceptualmente al final del trabajo, ¿responde a un propósito o a un desconocimiento sobre qué era Partidas a lo largo del siglo XIV? En definitiva, ¿estamos frente a un testimonio de cómo pudo llegar a funcionar Partidas dentro de la política ibérica o frente a una contingencia que nos está llevando más tiempo del debido? 


\section{Cancillería Real de Pedro IV: hipótesis sobre un proyecto recopilatorio}

La noticia dejada por Rubió Lluch sobre la autoría de la traducción al catalán de Partidas sigue suscitando fascinación y muchos interrogantes. Este autor afirmaba que dicha tarea había sido encomendada al real protonotario Mateu Adrià y contemplaba parte del proyecto cultural impulsado por el Ceremonioso, quien “encara que no en sentit humanístich, promogué gran nombre d'obres originals i traduccións" (Rubió, 1908, I, p. XXXI) ${ }^{10}$ Este tipo de mecenazgo ya había cobrado impulso en la época de Jaime II, convirtiéndose en una tendencia innegable en el reinado de su nieto (Hillgarth, 1992-1993, pp. 36-38; Verrié, 1989, pp. 177-192; Cawsey, 2002, pp. 49-54) y seguida más tarde por los hijos de Pedro, Juan I y Martín I (Tasis, 1994, pp. 35-38, 165-167, 213-217). De hecho, la inclinación intelectual de estos últimos reyes de la dinastía barcelonesa impulsó un precoz humanismo en la Corona de Aragón que tanto hizo para expandir la búsqueda por nuevos libros y traducciones de obras de varias procedencias para suplir las demandas de la corte y las bibliotecas reales (Cingolani, 1990-91, pp. 39-127; Gimeno, 2007, pp. 315-316, 322-328; Bacardí, 2012, pp. 181-184). ${ }^{11}$ Son bien conocidos los esfuerzos de estos monarcas por escribir nuevas crónicas que exaltaran las hazañas de la dinastía (Cingolani, 2019, pp. 15-38; Alchalabi, 2008, pp. 177-189), pero fue también bajo el impulso cultural de la realeza que se enriquecerían los acervos literarios catalano-aragoneses gracias a las seguidas demandas por crónicas francesas, inglesas y castellanas, así como por traducciones de tratados de teología, medicina, cartografía y de muchos autores clásicos que han sido traducidos del latín al catalán (Rubió, 1921, II, 91, pp. 142, 163-164, 219, 225-228, 256-259, 326-327).

Como su abuelo Jaime II (Péquignot, 2002, pp. 431-479), Pedro también jugó un papel muy destacado en la reforma de los archivos y de las bibliotecas reales. ${ }^{12}$ Basta una breve consulta de los fondos epistolares del rey Ceremonioso para comprender su afán por controlar los volúmenes que salían de los archivos a las manos de los copistas y demás oficiales de la curia. ${ }^{13}$ Como ha sido destacado por Sevillano Colom (1950, pp. 137-241) y, más recientemente, por Gimeno Blay, el crecimiento de las necesidades de la cancillería durante los años de Pedro IV ha elevado las funciones de los talleres de copistas, que iba más allá de expedir diplomas y protocolos de corte, y se convirtió poco a poco en un verdadero scriptorium real (véase Tomás, 2020, p. 154); es decir, este se transformó en el espacio oficial de la producción de libros hechos según los requisitos técnicos de calidad de elaboración textual y acordes con el uso más adecuado de los recursos materiales para su composición. ${ }^{14}$ Estas oficinas de cancillería vinieron en parte para superar la dependencia que tenían los funcionarios reales de los archivos de conventos y monasterios pero sin superarlos del todo (Cingolani, 2011, pp. 365-387) ${ }^{15}$. Esta red de fondos diplomáticos integró los scriptoria del clero con los nuevos archivos reales con el fin de mejorar los métodos de almacenamiento y de suplir las demandas por libros oficiales que circulaban entre los delegados regios dentro de los dominios de la Corona de Aragón. Los conocidos centros de difusión literaria de los siglos XI-XIII, como los monasterios de San Juan de la Peña, Santa María de Ripoll, Bellpuig de les Avellanes, Santa María de Poblet y Santes Creus (Cingolani, 2009, pp. 71-90), pasaron a formar parte de una organización más amplia centrada en la producción de libros: junto a los copistas del clero estaban los oficiales reales y también los particulares que trabajaron por iniciativa propia para producir manuscritos de uso no oficial (Gimeno, 2007, p. 328).

Debemos notar que las crecientes exigencias puestas sobre la formación y el entrenamiento de estos oficiales-copistas coincidieron con las reformas administrativas emprendidas por Pedro IV en los primeros años de su reinado. Estas mismas reformas estarían impulsadas por la nueva orientación legalista asumida por el rey tras la conquista del reino insular de Mallorca (1344) y los condados del Rosellón (1346), que fueron áreas de profunda influencia de los estudios de derecho romano (Elías de Tejada, 1963: I, p. 21; Abadal, 1972, p. 84; Ensenyat, 2018, pp. 7-8). En este contexto de movilidad de ideas e individuos dentro del cuadrante mediterráneo de la Corona de Aragón, es posible comprender el peso de los agentes que debían cumplir los requisitos de reclutamiento para poder acceder a los cargos oficiales de la administración pública (Estrada- 
Rius, 2017,pp. 50-52). Esto explica el papel del notario regio que -tras la nominación de Mateu Adrià el 7 de marzo de 1355 (Archivo de la Corona de Aragón [=ACA], Cancellería [=C], reg. 1025, f. 140v; d'Arienzo, 1981, pp. 150-151) - fue alzado al título de protonotharius y que ejercía un puesto superior al de los secretarios y demás auxiliares de escribanía (Conde y Delgado de Molina, 2008, pp. 50-51). Posiblemente data de este mismo período la inserción del protonotario en los ceremoniales de las Ordinaciones de la Casa $i$ Cort, ${ }^{16}$ cuyo papel ahora se acumula con el encargo de portasellos (tinent lo segells). Este trabajo debe ser ocupado por "persones dignes letrades e sufficients ab cura diligent", que en este caso eran los individuos designados por el rey para mantener la "custòdia e guarda dels nostres segells, en los quals la nostra real magestat és presentada, e per impressió dels quals les dites letres e cartes son obeÿdes e segellades” y que también se encargan de proveer "a correcció e a esmena de aquelles [lletres] si en bella retòrica o bon latí e juxta los nostre estil seran corregidores". Finalmente, era esperable que el venerado carácter moral, así como las habilidades técnicas del oficio se combinaran en la persona del protonotario para servir bien a los propósitos de la corte: "una bona persona de feeltat aprovada e almenys en sciència gramatical bé instruyda per Nós volem ésser aornada" (Gimeno, Gonzalbo y Trenchs, 2009, p. 123, III, 52).

En vista de los requisitos esperados de este cargo, Mateu Adrià llegó a ser designado como responsable o, al menos, potencial participante de los proyectos de compilación jurídica emprendidos por el monarca. La colaboración de Adrià en la cámara real está documentada antes de $1345,{ }^{17}$ incluso antes de que sustituyera a Francesc de Prohom (1349-1354) como el tercer notario de la cancillería de Pedro el Ceremonioso (Trenchs y Aragó, 1983, p. 57). Debido a esta larga proximidad con el rey, Mateu Adrià también fue considerado el traductor de las Ordinacions de la Casa i Cort, que derivan de la versión latina de las Leges Palatinae elaboradas para la corte de Jaime de Mallorca en 1337 (Lainé, 2009, pp. 19-20). Hoy, tanto la tarea de la traducción como la promulgación de las Ordinacions han sido extensamente estudiadas, dejando atrás las declaraciones de Sevillano Colom sobre la presumida autoría de Adrià en la traducción del ceremonial (Sevillano, 1950, pp. 141-148; Id., 1970, pp. 103-118). Sin embargo, lo que sí conocemos gracias a los estudios de Gimeno es que el propio Pedro IV fue uno de los protagonistas en el proceso de revisión de la versión "final" de las Ordinacions, según información bien estudiada por medio de los registros autógrafos que dejó el monarca en el ms. 1501, actualmente depositado en la Biblioteca de la Universitat de València. ${ }^{18}$ Gimeno concluye que es probable, por sus características gráficas, que este manuscrito provenga de la misma Cancelleria real ubicada en Barcelona (Gimeno, 2009: 38-40). Es cierto que junto a su corte el rey contaba con un centro formado tanto por copistas como por ciertos traductores especializados (Tomás, 2020: 164), así lo mencionaba el mismo Pedro IV en una carta al Infante Juan en 1373, indicándole el servicio habitual de aquellos copistas: "Com haurets mester libres que Nós hajam, fets-nos-ho saber e Nós farem-vos-en fer traslats, car ja tenim certs escrivans qui-ns fa trellats d'aquells libres que és necessari” (ACA, C, reg. 1238, f. 39; Rubió, 1908, I, p. 247).

Estos rastros pueden servir para estudiar nuevos elementos que aún no se han aclarado sobre las traducciones catalanas de Partidas. Aunque menos afortunado que la genealogía de las Ordinacions, los vestigios de esta empresa recopiladora realizada por Pedro IV indican un temprano interés por el código alfonsí incluso en los primeros años de su reinado, que coincidió en todo con las intenciones que impulsaron al monarca a llevar a cabo sus innovaciones de la cámara y de la distribución de la justicia real (Sabaté, 2016, pp. 293-328). Las rúbricas de las dos versiones catalanas de la Primera y Segunda Partidas, que se pueden encontrar en la Biblioteca de Catalunya (ms. 942, f. 10-148) ${ }^{19}$ y en el Monasterio de San Lorenzo de El Escorial (ms. M.I.2, f. 1-136; cfr. Iglesia Ferreirós, 1987, pp. 265-278; Cradock, 1986, p. 218) ${ }^{20}$, toman ciertamente el hecho de que estas traducciones salieron de la mano de Mateu Adrià. Es verdad que esta conclusión se apoya, a grandes rasgos, en la carta enviada por el propio Ceremonioso a la reina Leonor el 6 de julio de 1365, pidiéndole que busque a la viuda de Adrià para recuperar con ella los "iii libres de pergamí scrits de letra castellana formada e en lenguatge castella, en los quals libres son contengudes les leys del emperador, e 
han cubertes de posts ab cuyr morat vell". Sin embargo, nada de esto trasciende el habitual desplazamiento de libros de la cancillería para la consulta privada de los funcionarios reales. Sin duda, lo que más llama la atención en esta carta es la manifestación del rey de que esas copias en castellano de Partidas sirvieron para componer una traducción que él mismo había encargado previamente a su protonotario: "per tal que aquells fes tresladar en nostre lenguatge e fessem ordenar semblansts leys". El hecho de que se produjeran "originales", así como traducciones de Partidas ha superado el mero "interés erudito" alimentado por las apetencias bibliófilas de Pedro IV, hecho que también permite incluir estos textos en el conjunto formado por las Ordinacions de la Casa i Cort y las ceremonias de coronación (Aurell y Serrano-Coll, 2014, pp. 66-95; Tomás, 2020, p. 162). Porque, como el propio monarca había dejado claro, el principal objetivo de traducir las Partidas al catalán estaba en absorberlas como una nueva parte del repertorio legal regio: "les quals propiament poguessen esser dites nostres" (Rubió, 1908, I, p. 206). Asimismo, es difícil precisar cuánto del código alfonsí fue realmente traducido por Mateu Adrià, quien posiblemente no tuvo mucho tiempo para dedicarse a la traducción sin descuidar sus enormes tareas de cancillería.

De las versiones traducidas que aquí citamos destaca un fragmento extraído de la Segunda Partida y que se utilizó como libro independiente en el Tractat de Cavalleria de Pedro IV. Este texto fue publicado inicialmente por Bofarull sin ningún indicio de que fuera una traducción del código alfonsí, con el sencillo título de Obre de mossen sent Jordi e de cavalleria (1850, VI, pp. 21-65); sin embargo, más tarde la verdadera procedencia del Tractat fue indicada por Siegfried Bosch (1936, pp. 655-680), lo cual ha sido reeditado por Bohigas (1947: 29-30; Cradock, 1986, p. 29). Como bien señaló este último, el cuerpo del tratado que pertenece a la Segunda Partida es claramente distinto del prólogo allí insertado, quizá de la mano del propio Ceremonioso (Sabaté y Soriano, 2015, pp. 158-159). Este prólogo es un ejemplo de los argumentos híbridos adoptados por el príncipe que quiere justificar simultáneamente la primacía de su posición por el deber de lealtad de sus súbditos con el pacto señorial y por el carácter público de su principado: "attenents que.ls reys e.ls prínceps del món als quals és dada (...) del regiment de lurs sotsmeses, axì com per furs, leys e constitucions han a governar e a tenir lurs estaments e regir los pobles a ells per la sobirana providència comanats" (Bohigas, 1947, pp. 98-99). Esta ideología regicéntrica, mezclada con el programa práctico de gobierno del rey Pedro IV, resalta las circunstancias particulares que motivarían la producción de los textos que aquí mencionamos y que finalmente deben ser cuestionados a la luz de los planes reformistas de una monarquía que vivió en constante enfrentamiento con los poderes baroniales que eran refractarios a los intentos centralizadores del trono (Sabaté, 2009, pp. 1-15).

\section{ALgunOS TRAZOS HISTÓRICO-LEGALES: LAS REFORMAS DE GOBIERNO Y EL INTERÉS POR LAS PARTIDAS}

La incorporación de nuevos repertorios textuales para la administración regia representada por la traducción de Partidas y Leges Palatinae encuentra justificaciones relevantes en el campo jurídico-político. El proyecto liderado por Pedro IV para ampliar los marcos legales de su gobierno a partir de la recepción de fuentes foráneas corresponde sin duda al contexto de los años 1330-1350, en los que se intentaron cambios de gran calado en el gobierno. Esto se debía a que la necesidad de expansión interna y externa del poder real dependía de una fusión de bases teóricas y materiales a disposición de la monarquía (Bertran, 2005, pp. 1-22; Ferrer, 1970-1971, pp. 357-370). La patente escasez de recursos crematísticos del tesoro real que caracterizó la condición constante de la monarquía aragonesa ${ }^{21}$ y las demás dinastías peninsulares (Gomes, 2003, pp. 49-55), obligaría pronto a sus monarcas a buscar formas de ampliar el control de la justicia y los ingresos obtenidos a través de los contratos de cesión dominial integrados con su patrimonio. En este contexto, se debe considerar dentro del escenario político el peso de los sucesivos efectos de la crisis social derivada de la hambruna, así como los avances de la peste que, desde lo mal any primer (1333), devastó la población del Principado (Mutgé, 2001, pp. 649-660; Benito, 2004, pp. 179-194). Si las consecuencias de esta crisis 
afectaron los dominios directos del rey, recayeron aun más pesadamente sobre las jurisdicciones baroniales, que pronto vieron reducidas sus rentas y se encontraron forzadas a aceptar los discursos "autoritarios" de la jurisdicción monárquica. El tácito reconocimiento de que el príncipe ejercía la autoridad pública sobre todos los vasallos del reino ayudó a avalar nuevas pretensiones políticas de realeza en el campo de la doctrina jurídica, de ahí la creciente elaboración de dictámenes legales (producidos por iniciativa monárquica, aunque no fuesen solo limitados por ella) reforzó la naturaleza híbrida del titular regio, la cual estaba doblemente basada en la tradición "feudalizante" de la senyoria natural y en la pretensión de superioridad del príncipe justificada por la tutela de la necessitas publica (Tostes, 2020, pp. 86-112).

Los reyes aragoneses siguen este doble poder para ganar nuevos campos en los que aplicar lapublica potestas. Ante los representantes de la tierra reunidos en las cortes generales, el Ceremonioso reiteradamente exhibió el mismo argumento del contrato político que vinculaba a los súbditos con su soberano, una ligadura natural santificada por la pertenencia de todos los hombres de la terra (ACA, C, reg. 1499, fl. 20), pero con el añadido de que la potestas por entero resulta del otorgamiento racional en ese marco publicista. En este sentido, queda evidenciada la propaganda regia de Pedro IV, comprometida a intensificar una nueva conexión simbólica de este arcaico fundamento natural entre el príncipe y sus súbditos. Los fragmentos de Partidas traducidos al catalán por orden del propio monarca pueden sustentar esta ideología política tan difundida por los expedientes de su cancillería y por los libros de instrucción jurídica y moral. Como explicita el Tractat de cavalleria, donde esta ideología fue subrayada en el prólogo añadido por Pedro IV, "Naturalea o vassallatge son los maiors deutes que homens podem haver ab son senyor, car la naturalea sempre toca a tot per a volerlo e amar-lo e no anar contra ell e el vassallatge per a servir-lo lealmente". ${ }^{22}$ En suma, la primigenia titulación soberana del príncipe conferida por los Usatges de Barcelona (Iglesia Ferreirós, 2005, pp. 3-84), y después reelaborada por las Commemoracions del jurista Pere Albert a finales del siglo XIII, sigue estando limitada por un "horizonte feudal" de aplicación en el paisaje jurídico catalán (Ferran, 2006, pp. 238-247; Sabaté, 2006, pp. 93-103).

De algún modo, los cambios prácticos y teóricos de la concepción regia de este poder público adquieren importantes suplementos desde los reinados de Jaime II y Pedro IV, pues como decíamos, ambos monarcas realizaron conscientemente reformas que se apoyaron en concepciones jurisdiccionalistas tomadas en la raíz del ius commune. Sin embargo, el alcance de estas reformas se ha puesto a prueba con los barones de Aragón y Cataluña que a veces las aceptaban o, como más a menudo ocurría, las rechazaban in toto. El período que siguió a la incorporación del reino mallorquín señaló un capítulo particularmente interesante en el proceso de asimilación de los dominios continentales en Rosellón. Este estuvo marcado por las estrategias de Pedro IV a la hora de intentar profundizar los lazos de base jurídica que retomarían los vínculos consuetudinarios del derecho catalán de acuerdo al marco de los Usatges. Es lo que se aclara con el ejemplo de los privilegios otorgados por el rey a la villa de Perpiñán en 1344: "gaudere libere valeatis prout melius et plenius in ceteris locis Cathalonie observantur consuetudine ville Perpiniani qua caveatur, quod Usatici Barchinone non vendicant sibi locum infra dictam villam vel quovis alio usu contrario non obstante". ${ }^{23}$ Esta línea de experimentos todavía se lleva a cabo dentro del alcance de las aplicaciones probadas con las Consuetudinem Ispanie en los mismos dominios roselloneses ahora diseñados como un nuevo régimen de tenencia de castillos (Sabaté, 2006, pp. 100-114) ${ }^{24}$. Este es el nombre que da la legislación catalano-aragonesa a los extractos de Partidas así incorporados u ocasionalmente citados en contratos de cesión de dominio, los cuales se remontan al menos a principios del siglo XIV. El tema ha sido estudiado por Ramon d'Abadal en su tesis doctoral (1914, pp. 1-105). ${ }^{25}$ Sin embargo, no existía una clara evidencia que sustente la hipótesis de que la traducción de Partidas (Iglesia Ferreirós, 1987, pp. 265-266) coincidiera con las primeras iniciativas de la monarquía aragonesa en su intento de reemplazar los antiguos modelos feudales de los Usatges y Costums de Catalunya (ACA, C, reg. 1462, f. 125v, 186r-187v) por los usos contenidos en el código alfonsí (Montagut, 1995, pp. 487-505). Es decir, Ramon d'Abadal quiso interpretar las innovaciones introducidas en la primera mitad del siglo XIV con la recepción de las fuentes jurídicas castellanas a lo que él mismo denominó como "moviment 
teòric" impulsado por Pedro IV, rey de notorias tendencias autocráticas, y que procedía como "l'entusiasta de les Partidas que arriba fins a fer-les traduir amb finalitat d'adaptació jurídica” (Abadal, 1970, II, p. 355). Por otro lado, Flocel Sabaté demostró recientemente que mucho antes de que comenzara el reinado de Pedro IV ya se podía documentar en la Corona de Aragón unas concesiones de fortalezas bajo el régimen de las Consuetudinem Ispanie (ACA, C, reg. 424, fl. 8r; reg. 561, fl. 116v; Sabaté, 2006, pp. 112-114; Ferrer, 1988, pp. 1-102). Sin embargo, el fenómeno de revitalización de regímenes de este tipo observado en los territorios roselloneses recién incorporados por el rey de Aragón (1344-1350) apoya la hipótesis de un esfuerzo global de la cancillería para ampliar los mecanismos de centralización según un instrumento legal allí fabricado y que estaba destinado a su propio uso.

\section{Partidas aragonesas en castellano: proyecto político a partir de los retazos de UN PROYECTO POLÍTICO}

Existe una serie de elementos histórico-contextuales de la monarquía aragonesa que arrojan pruebas para acercarnos a una hipótesis razonable sobre la inserción del neoyorkino en dicha realidad. Resaltan las traducciones de Partidas, muestra insoslayable del interés sobre la compilación jurídica alfonsí. El HS1 no cumple con esta condición, pues fue escrito en castellano, pero no deja de ser interesante traer al ruedo el profundo interés de Pedro sobre Partidas ni, más aún, la utilización que hizo sin referir directamente a ellas, como se ha subrayado y comprobado en torno a la cita sobre naturaleza y vasallaje (solo por poner un ejemplo entre tantos): "Naturalesa o vassallatge son los maiors deutes que homens podem haver ab son senyor, car la naturalea sempre toca a tot per a voler-lo e amar-lo e no anar contra ell e el vassallatge per a servir-lo lealmente" (Abadal, 1914, p. 97), y que es traducción literal de Partidas 2.18.32 "Naturaleza e vasallaje son los mayores debdos que ome puede aver con su señor. Ca, naturaleza le tiene siempre atado para amarlo e non yr contra él, e el vasallaje para sevirle lealmente". A este uso cabe sumar el interés por la obra en castellano, de la cual sabemos hay registros en la medida que fueron utilizadas para la propia traducción.

Ahora bien, el punto a detenernos entonces es sobre la presencia de copias castellanas para considerar el evidente trabajo de refundición realizado sobre el neoyorkino. En rigor, aunque el contexto no se ajusta aritméticamente, hay un proyecto que funde las monarquías en una sola. Estos proyectos, característicamente, son propios de tres instancias. El alfonsí, propiamente, en su siglo XIII, el de Alfonso XI, cuya concreción manifiesta se produjo en 1348 y el de Pedro IV, que ocupó los años centrales de 1345-1380. De algún modo, en cada intención "centralizadora" basada en la idea de jurisdicción concentrada apareció Partidas como base teórica para el desarrollo material de dichas pretensiones. Como ya se dijo, estos proyectos, en especial el de Alfonso X y el de Pedro IV, fueron culturales y no solamente de reforma jurídico-política. Lo cual conllevó al desarrollo de un repertorio de obras, muchas, sino la mayoría, en castellano para satisfacer la demanda "libresca" de un territorio en pleno desarrollo. Así, las influencias y los tráficos intelectuales superaron por mucho indicadores concretos y específicos para transformarse en un movimiento donde la circulación de obras, usos (en su sentido más medieval, i.e., apropiar y cambiar según circunstancias del hablante/compilador/copista). Todo este movimiento no puede circunscribirse, como se vio, a una decisión única y aislada, sino que respondió a una tendencia de la Corona de Aragón y que comenzó con Jaime II. No contentos con ello, a la exigencia "cultural", empresa clave de cualquier desarrollo monárquico, se sostuvo la necesidad de la cancillería de dotar de dispositivos jurídicos con los que elaborar teoría y materia ajustada a la realidad del proyecto del Ceremonioso. En consecuencia, el scriptorium real conformado en el valle del Ebro durante la segunda mitad del siglo XIV propuso y dispuso de una profusa cantidad de obras para crear y justificar un proyecto político y cultural.

La necesidad creciente de texto legislativo válido y promulgado conllevó la multiplicación de fuentes jurídicas, siendo Partidas una de las predilectas de Pedro. En ese contexto, integrar Partidas no podía referir solamente a traducir lo enunciado por un castellano. No solo por su condición foránea, sino, principalmente, 
por la necesidad objetiva de adaptar la compilación alfonsí a una realidad propia. Esta realidad, quizá más cercana a la castellana de lo que a Alfonso X le hubiera gustado reconocer, no eludía la virtual autonomía de poderes territoriales y locales que debían reconocer una fuente unilateral de derecho y, en rigor, política. Esto es lo que podría haber motivado esos conceptos de carácter híbrido entre la posición de potestas publica que se pretendía ejercer al mismo tiempo que una posición de primacía relativa por medio de un sistema de lealtad. Esta noción permitiría considerar el proyecto cultural petrista como del paso de una ideología regicéntrica a una iuscéntrica. ${ }^{26}$ No como etapas o contradicciones, sino como elementos que se solapan en la medida que, en Partidas, el rey y la ley se funden. ${ }^{27}$

El neoyorkino muestra características fundamentales: se denotan diversas manos, mucha atención a la corrección (aunque a lo largo del testimonio estas van a la baja), una condición de refundición en lo que hace a su relación con las tradiciones de Partidas, marcadas por interpolaciones larguísimas de Setenario y, finalmente, una marcada tendencia sapiencial y profundización de temática religiosa. ${ }^{28}$ De por sí la Primera Partida está dedicada a ello, a excepción de los primeros dos títulos que se podría decir definen una teoría del derecho a través de las definiciones de ley, uso, costumbre y fuero. Sin embargo, la inserción de la lógica numerológica, donde se borrará la dependencia del siete en las interpolaciones presentes en HS1, le otorga un carácter marcadamente observante de lo "religioso" a este testimonio. Asimismo, las interpolaciones son por momentos desmedidas y rompen con la lógica discursiva alfonsí, no solamente por la adición de material no presente en cada título, sino por una extensión desmedida de las leyes. En ese sentido, se sale de la lógica alfonsí de la ley paladina y llana. ${ }^{29}$ Estas inserciones no parecen producto de la confusión entre ambas obras, no parecen un error. Parece claro que entendían qué era Partidas y qué Setenario. Como mostraremos en la siguiente sección, la adaptación del medianamente complejo sistema de numeración de leyes, elementos y subelementos que se produce con dichas inserciones es una muestra de la consciencia creativa sobre el neoyorkino. Una creatividad que, creemos, responde mejor al interrogante original, el de un ensayo. Sin embargo, este ensayo no habría pertenecido al scriptorium castellano, sino a uno aragonés de Pedro que buscaba en la síntesis romano-feudal la expansión del ligamen simbólico que permitiera profundizar los vínculos entre súbditos y rey, siendo la naturaleza un concepto crucial, como deja claro su utilización dentro del Tractat, y que es esencial en el sistema discursivo-teórico alfonsí del poder del rey. ${ }^{30}$ A esta base, que es teológica per se, pero también deudora del sistema filosófico-aristotélico, en su vertiente árabocordobesa, se sumó el énfasis que Setenario coloca a la regulación de la vida civil en términos de una suerte de catequesis de la vida cotidiana. La posibilidad de determinar el más allá y la conexión con él hic et nunc, implica, justamente, la posibilidad de determinar ese "más acá" sobre el que se pretende fundar el proyecto cultural, pero que también es político y jurídico. El material creativo es el resultado de un esfuerzo global que comprendía múltiples dimensiones y escenarios de actuación de la monarquía en un momento donde no existían regímenes discursivos, ni de la realidad, perfectamente delimitados unos de otros. En este sentido, es probable que el neoyorkino no nos hable de la relación entre Partidas y Setenario ni del proceso final de reredacción de la Primera Partida. Lo probable es que nos hable de una realidad distinta, geográfica, temporal y política. Asimismo, lo claro es que nos habla de la potencia y función del discurso jurídico alfonsí, ya no sobre Castilla, sino sobre la Península entera.

La letra del manuscrito, aunque revela distintas manos, como se dijo, es una gótica cursiva aragonesa de transición a bastarda (Pichel, 2021). Asimismo, las soluciones gráfico-lingüísticas (alternantes o asimétricas) son propias de un hablante del aragonés (Pichel, 2021). Finalmente, la cubierta y demás elementos de ese corte conducen a pensar en Teruel o la parte meridional aragonesa en general como contexto de producción (Pichel, 2021). De algún modo esto coincide con la producción textual de compilaciones de fueros en la zona, aunque con muchos interrogantes específicos sobre esta producción. En primer lugar, debemos proceder al análisis filológico detenido para demarcar los límites del producto textual. Hasta qué punto el cambio de manos respondió a cambios en el material tratado, como sostiene Pichel (2021), hasta qué punto pudo 
viajar y en Teruel solo terminar. Asimismo, el análisis filológico profundo nos dirá qué estamos leyendo en cada ley y cómo se llevó adelante la composición. Esto, que será propio del próximo trabajo de edición del manuscrito que se pretende para 2021-22, tendrá un nuevo punto de inicio: la hipótesis de haber constituido una propuesta original para la Corona de Aragón como elemento teórico que permitiera construir desde su carácter jurídico una proposición contundente que coadyuvara a cimentar un lazo simbólico duradero entre la monarquía aragonesa y sus súbditos. Si esto pretendió, lo hizo del mejor modo posible en términos alfonsíes, echando mano a todo cuanto pudiera servir a concretar la intención comunicativa de la compilación.

\section{No eS LA MEDIDA DE LA INTERPolación: un ATISBo CRÍTICO PARA UNA TEORÍA DE PARTIDAS COMO MACROESPACIO LITERARIO}

En la ley 40 del quinto título del neoyorkino se expone una profunda y larga interpolación que se corresponde con la ley 94 de Setenario. Los cambios producidos en el testimonio intervienen no solo en la condición y unidad textual de Partidas (si tal cosa pudiera existir), sino en el mensaje y el propio modo en que comunica su mensaje. De algún modo, estos procedimientos de intervención, que han sido constantes con el texto jurídico alfonsí, se presentan en este testimonio con una potencia insoslayable y, a la vez, que provoca un fenómeno nuevo; pues, a diferencia de la intervención que produce la escritura marginal o de la composición de un manuscrito por vía crítica en tiempos medievales o temprano modernos, el HS1 muestra una composición creativa que borra los condicionantes discursivos del derecho alfonsí. ${ }^{31}$ Este procedimiento quiebra no solo la teórica unidad del texto alfonsí, sino también su propia sintaxis y modo de composición de la ley (modo incluso teórico de composición y transmisión de ella). Esta circunstancia propia del neoyorkino no es excepcional del ejemplo dado supra. Cierto es que la cantidad y calidad de interpolaciones es, aunque variable, sostenida. El ejemplo entonces es traído a este estudio como botón de muestra para describir el proceder de los escribas del HS1 y, de allí, intentar explicar si hay un funcionamiento discursivo más que una circunstancia histórico-textual.

Sistemáticamente, se ha colocado al testimonio en cuestión como cercano o perteneciente a la tendencia legalista más antigua de la tradición manuscrita. ${ }^{32}$ Como asentó García y García (1963) en su examen estructural del testimonio, no hay casi correspondencias entre sus títulos y leyes con las del resto de los testimonios. Aunque temáticamente hay títulos que se corresponden con el título anterior, el cuarto, las leyes dentro difieren y solo hay una correspondencia parcial de algunas de ellas, ninguna es la señalada aquí, con otros testimonios de la tradición: los ligados a la corriente sapiencial. ${ }^{33}$ García y García señaló que esa correspondencia indicaba cercanía al manuscrito 580 (D. 9), identificado como Biblioteca Real $1^{\circ}$ por la edición de 1807, es decir, el manuscrito MN2, según la nomenclatura actual dada por el proyecto Siete Partidas Digital. Este testimonio no es un representante optimus de dicha tendencia, pero refleja el estado de refundición que queremos subrayar. ${ }^{34}$ Ahora bien, el contenido, o una parte, del título quinto del neoyorkino se corresponde, aunque solo en algunas leyes, con el título cuarto del MN2 y, en su estructura, sucede lo propio con el manuscrito LBL. La correspondencia entre título y ley arroja esto mismo que ya sindicamos para el anterior testimonio. Así, en LBL se expresa en 1.5.40 que: "Symonia faziendo algunos en orden, no puede el obispo dispensar con ellos". Mientras que HS1, 1.5.40, indica: "Como deven saludar a la crisma depues qu'es fecha, et porque raçon. Saludacion es palabra que deve decir un omne a otro que sea su amigo (...)". El punto queda claro sin la necesidad de avanzar con ejemplos. Los textos son distintos en el mismo lugar. Pero, asimismo, el contenido del HC 397/573 no se encuentra así en otra parte de los testimonios mencionados. El problema expresado no se soluciona reordenando cuadernillos, problema que también tiene el HS1. El punto central es la acción ejercida sobre el texto forzando su código con la intención, quizá de crear algo nuevo o, tal vez, reunir la multiplicidad de lo que se consideraba todo lo mismo (incluso distinguiendo Partidas de Setenario como se dijo supra). 
García y García (1963) sostuvo que este testimonio resguardado en la ciudad de Nueva York es una reelaboración post-alfonsí. Por su parte, Craddock (1986, p. 448) sugiere, con carácter dubitativo, que el testimonio neoyorkino podría representar un cuarto estado de la cronología de $S P$ (o uno intermedio). En nuestra opinión, el manuscrito HS1 no es una reelaboración de Partidas ni un cuarto estado. Hay dos cosas que complejizan un problema ya con bastantes aristas: por un lado, es cierto que el neoyorkino es una refundición post-alfonsí. Por otro lado, tampoco es un representante de un estado nuevo (o redacción, para tomar el léxico expuesto por nosotros y que Craddock usaba en 1981 para referir a esto mismo). El título y prólogo así lo demuestran. Si los análisis sobre el título de $S P$, sus epígrafes y prólogos (es decir, sus elementos paratextuales) han sucitado controversias, debates y teorías, por qué descartar esos mismos elementos para considerar la "naturaleza" del neoyorkino. En el caso de Partidas, tanto el título como el prólogo demuestran una función discursivo-enunciativa que denota la operación textual que es, a su vez, la clave de la heterogeneidad intertextual de la obra. Genette expresa que el título (como demás elementos paratextuales) implica una relación explícita que permite distinguir dos planos discursivos diferentes. Una suerte de umbral que denota heteronomía pero que, a la vez, está al servicio de otra cosa: el texto (1982). Si está al servicio del texto, lo expresa, lo denota. Decir esto es lo mismo que decir que ejerce un control discursivo (Zoppi Fontana, 2007). A veces la teoría moderna empaña más que aclarar el estudio de testimonios medievales. Sin embargo, creemos que lo precisa en la medida en que el título puede constituirse como una marca de circulación (Genette, 1987). Es decir, el título produce un efecto, tiene una función. Dicha función se relaciona de modo directo con los lectores. El neoyorkino, sin embargo, no tiene título propiamente. Solo se revela dentro del prólogo, elemento paratextual al que le caben muchas de las mismas disquisiciones propuestas. Así, la primera línea (con una palabra sobre la segunda) nos indica que este es el "libro del fuero de las leyes". Es decir, hay una evocación directa al título; una determinación temática de lo que sigue a continuación de la tabla de contenidos. En este caso, remite a la primera redacción de Partidas. Sin embargo, a lo largo de la obra encontraremos elementos de la segunda y tercera redacción. En ese sentido, la elección del título (o mejor dicho del prólogo) es una derivación de los discursos que evoca las entidades lingüísticas que componen el testimonio (Authier-Revuz, 1984). Si el neoyorkino fuera una cuarta redacción de $S P$, ¿ por qué remite al título de la primera? Esto no es menor, pues a partir de la segunda redacción estaría dispuesta ya la presencia del siete como elemento remático de la obra. Más aún, siendo Setenario posterior y última refundición de los primeros cuatro títulos de Partidas, este elemento anterior pero inmediato debería reflejar el siete con mayor claridad. ${ }^{35}$ No solo no lo hace en el título, sino que no lo hace a lo largo de toda la obra. De hecho, en la interpolación con la que abrimos esta última sección se muestra el borramiento deliberado que se ha hecho del "siete interno" para que el carácter distintivo de Setenario tampoco esté presente. ${ }^{36}$ Finalmente, no solo se borra Setenario sino, por este mismo proceder, Partidas, pues su sintaxis y, con ella, la propia teoría jurídico-discursiva alfonsí (que implica su forma de escribir y transmitir la ley) es destruida en función de construir leyes nuevas que posean un contenido refundido "perfecto" donde todo aquello que a finales de siglo XIV pudiera haberse considerado $S P$ estuviera presente. En sus dos tendencias, legalista y sapiencial (Panateri, 2021), Partidas denota una estructura argumental trabada. Aunque cada uno de estos registros muestra formas de ilación distintas, lo cierto es que la síntesis y la trabazón son la marca distintiva de la obra (Cano Aguilar, 1989 y 1996; Lodares, 1996; Lacomba, 2004; Panateri, 2013 y 2017). En el testimonio HS1 esto desaparece, en particular en lo que hace a la extensión de las leyes y su relación interna (tanto de las propias leyes como dentro de cada título).

Todo lo dicho hasta aquí nos conduce a la última consideración: el manuscrito neoyorkino es un testimonio híbrido (Pichel, 2021). Desde el punto de vista textual esto es insoslayable. Sin embargo, esta ponderación del producto textual nada dice sobre su función ni su porqué. Sobre lo que no hay discusión es sobre el hecho de que es una muestra única. No hay otro igual. La operación textual de mayor incidencia es la interpolación. La pregunta es si esta forma de intromisión textual busca corromper o, en realidad, crear. 
La interpolación en tanto operación textual suele ser calificada como contaminación. Eso es, una suerte de error, consciente o inconsciente, que quita originalidad. Sin embargo, la producción cultural medieval no prevé el concepto de originalidad tal y como nosotros podríamos comprenderlo. La interpolación puede ser vista, primariamente, como una relación (al igual que otros elementos paratextuales, pues quizá la interpolación sea esto mismo) entre lectores y textos en diversas épocas (Tarrant, 1987). La clave del trabajo de Tarrant se basa en considerar que:

[luego de mencionar otras formas paratextuales] There is another form of interpolation, however, which poses a much serious challenge to our historical imagination, baceause it reflects a way of responding to literature that is no longer natural to us. My name for it is imitation or collaboration, and its distinctive mark is a desire to prolong, to elaborate, or even to surpass the text which inspires it. (Tarrant, 1987, p. 295)

El punto central ahora es hasta qué punto podemos hablar de interpolación y en qué momento podemos hablar de refundición. Esto último quedará para un próximo trabajo. A priori, el uso del título (que refiere a una primera redacción) y estructura de Partidas nos somete a pensar que se pretendió que esta obra sea considerada como tal y no como una completamente nueva, amén del trabajo realizado. En la muestra que colocamos a continuación puede apreciarse algo del trabajo realizado sobre el HS1. Hemos cortado las transcripciones por cuestiones de espacio. El punto a destacar es que mientras Setenario acomoda la ley conforme al siete, en el neoyorkino se presenta unida a través del uso de estructuras paractácticas, por momento a través del polisíndeton y otras a través de elementos consecutivos. Hemos pareado las muestras para que pueda apreciarse el parecido y las diferencias. 


\begin{tabular}{|c|c|}
\hline Ms neoyorkino (33v.b-34r.b) ${ }^{1}$ & Setenario (pp. 170-73 de la edición de Vanderford) ${ }^{2}$ \\
\hline $\begin{array}{l}\text { Ley XL. Cómo deven saludar a la crisma depués qu'es } \\
\text { fecha, et por qué raçon. }\end{array}$ & $\begin{array}{l}\text { Ley XCIV. De cómmo deuen bolver el olio de la crisma } \\
\text { con del olio del bálsamo. } \\
\text { Boluer deven el olio de la crisma con el del bálssamo, } \\
\text { (...). } \\
\text { Et por ende estableçieron los santos padres que quando } \\
\text { los boluyesen vno con otro, que lo ffiziesen en siete } \\
\text { maneras: la primera, (...), la tercera, por ssaludamiento, } \\
\text { (...). }\end{array}$ \\
\hline $\begin{array}{l}\text { Saludación es palabra que deve decir un omne a otro que } \\
\text { sea su amigo o lo desea ser, porqu'es grand segurança } \\
\text { de amiztad, diciendo: que Dios le de salut, (...). }\end{array}$ & $\begin{array}{l}\text { Et la terçera, por saludaçión, ésta es palabra natural que } \\
\text { deue dezir vn omne a otro que ssea su amigo o lo deua } \\
\text { sser, por que muestra grant signifficança de amiztat, } \\
\text { diziendo que Dios le dé salut; (...). } \\
\text { La quarta es que el obispo deue ssaludar la crisma. }\end{array}$ \\
\hline $\begin{array}{l}\text { Et por ende, estableció santa Eglesia que despues qu'el } \\
\text { obispo la oviese bendicho, (...). }\end{array}$ & $\begin{array}{l}\text { Esto estableçió Ssanta Eglesia, que después que el } \\
\text { obispo la ouyere bendicha, (...). }\end{array}$ \\
\hline $\begin{array}{l}\text { Et depués qu'el obispo la oviere saludada [h]an la de } \\
\text { saludar las personas más honradas et los sacerdotes que } \\
\text { y estudieren, (...). }\end{array}$ & $\begin{array}{l}\text { La quinta, que la deven ssaludar las perssonas más } \\
\text { omrradas e los ssaçerdotes, e es esto que después que } \\
\text { el obispo la ouyere ssaludada, hanla ssaludar las } \\
\text { personas más onrradas et los ssaçerdotes que y } \\
\text { estudieren, (...). }\end{array}$ \\
\hline $\begin{array}{l}\text { Et depués que la ovieren saludado por tres veçes [h]an la } \\
\text { de poner sobre el altar o sobre una mesa que sea } \\
\text { cubierta de paños blanchos de lino, }\end{array}$ & $\begin{array}{l}\text { La ssesta, que depués que la ouyeren ssaludada, la } \\
\text { deuen poner ssobre el altar, esto es que la deuen } \\
\text { saludar tres vezes. (...). } \\
\text { (...) pannos de lino muy blancos. }\end{array}$ \\
\hline $\begin{array}{l}\text { et la raçón porque stableció santa eglesia, porque se } \\
\text { umiliase a la crisma quando la saludase fue porque así } \\
\text { como los judios (...), }\end{array}$ & $\begin{array}{l}\text { La ssetena, la rrazón por que estableçió Ssanta Eglesia } \\
\text { que sse homillasen a la crisma quando la ssaludasen } \\
\text { ffué porque assí commo los judíos (...). }\end{array}$ \\
\hline $\begin{array}{l}\text { (...), onde recibieron salvamiento en cuyo regno han de } \\
\text { regnar spiritualmente. }\end{array}$ & $\begin{array}{l}\text { (...), e dende rreçibieron la saludaçión e cuyo rregno } \\
\text { spiritual non ha ffin, et con ella sson vuntados ssus } \\
\text { ssiervos. }\end{array}$ \\
\hline
\end{tabular}

La relación entre ambos textos es clara. Este ejemplo se repite a montones en el neoyorkino. Al respecto, Craddock (1992) propuso un análisis donde quedaba demostrada la cercanía entre dichos testimonios. El punto clave de las influencias es cómo calificarlas. A primera vista, resulta claro que no podemos hablar stricto sensu de interpolación. Ni siquiera poniendo en crisis el concepto podemos atribuir este fenómeno 
textual a una interpolación colaborativa. Sin embargo, podemos quedarnos con algo. No estamos delante de una refundición ad litteram tampoco. En algún momento un grupo de personas realizó este trabajo donde Setenario pasó a formar parte del neoyorkino. Prima facie, siguiendo los lineamientos de la ilación jurídica alfonsí, la adaptación de uno a otro parece perfecta. Con el correr de la lectura, aparecen otros elementos ya mencionados, donde se produce aquella "destrucción" de la forma de escribir la ley alfonsí que mencionamos supra. Un ejemplo destacado puede ser el de la ley 21 ("En qué logar et cómo deve ser fecho el cathecismo") que abarca desde el folio 19r.a al 22r.b. ¿Es esta ley, como tantas otras, la consecuencia de un trabajo segmentado? Las distintas manos presentes en el manuscrito denotan distintas calidades e, incluso, diversas variantes dialectales. La pregunta más importante es por qué realizaron este tipo de trabajo. No nos referimos a la adecuación en sí, sino a refundir Setenario dentro de Partidas borrando Setenario y mantiendo una identidad con Partidas, pero a través del título de la primera redacción. ¿Podría ser que a fines del siglo XIV circulasen estas obras de modo indistintos? a priori, luego del Ordenamiento de Alcalá de 1348 donde quedó fijado un texto de Partidas no parece probable, como ya sugerimos. Asimismo, en dicho ordenamiento, creemos, el nombre de Partidas estaba consignado. Además, atentos a lo dicho en el segundo, tercer y cuarto apartado, el espacio y tiempo de creación del neoyorkino demuestra que dentro de los límites de la Corona de Aragón conocían muy bien el texto castellano. Ni las copias en esa lengua ni las traducciones al catalán hechas en tiempos de Pedro IV revelan estos procedimientos. Sin embargo, es cierto que, como ya asentamos, la posibilidad de la creación y modificación para darle nuevo impulso a algo ya conocido era algo habitual. No referimos a la forma de producción cultural medieval en general, sino a las políticas jurídico-culturales de Pedro IV y su entorno que asentamos en la sección previa. Entonces, ¿HS1 podría ser un borrador? ¿Un intento nuevo de "conçertar las dichas leyes et escrivirlas en un libro que mande tener en la mi camara", como dice el promedio del Ordenamiento ${ }^{39}$. Cierto es que este manuscrito no fue guardado en ninguna cámara regia.

Quedan más interrogantes que respuestas. El próximo paso es la edición completa de este testimonio guardado en Nueva York con un estudio pormenorizado de todos los elementos textuales que presenta, que son por centenas, y aquí solo vimos someramente. ${ }^{40}$ De lo analizado se desprenden algunos elementos firmes. Sea interpolación colaborativa, refundición a medias o re-compilación el HS1 muestra un fenómeno que debe ser explicado no solo por sus condicionantes textuales, sino también por los históricos con el fin de ponderar el hecho de que su importancia está dada por la potencia y función del discurso jurídico alfonsí, ya no sobre Castilla, sino sobre la Península entera. Hemos visto que el reinado de Pedro el Ceremonioso fue propicio para este tipo de creaciones. Asimismo, coincidimos en ubicar este testimonio dentro de sus márgenes espacio-temporales. Hemos visto también que hay una evidente pretensión discursiva, la cual es anterior al acto enunciativo. Difícilmente estemos frente a un eslabón perdido del proceso redaccional alfonsí, sino más bien frente a un intento tardío de crear algo a través de homogeneizar toda la producción jurídica alfonsí que se tenía a la mano. Detrás de esto hay un objetivo que debe ser desentrañado. Creemos que el mejor modo es yendo de lo textual a lo histórico. Lo innegable es la importancia que el neoyorkino guarda para la historia de Partidas, de su transmisión y circulación, pero más aún de su función (o funcionalidad) política, jurídica y cultural. HS1 es, en definitiva, un elemento monstruoso que permite, a la vez, echar luz sobre el cómo y el para qué de la existencia de Partidas desde el siglo XIII en adelante. La excepción, el caso margen, que nos guía sobre el cómo y no el qué de Partidas y su historia.

\section{Material Primario}

HS1 - MS HC 397/573 The Hispanic. Museum \& Library, Nueva York. 


\section{BIBLIOGRAFÍA SECUNDARIA Y PRIMARIA CITADA}

Abadal, R. (1914). Les 'Partidas' a Catalunya durant l'Edat Mitja. Revista d'estudis universitaris catalans, 6-7 (extret), 1-105.

Abadal, R. (1970). Dels Visigots als Catalans. La formació de la Catalunya independent. Barcelona: Edicions 62, vols. I-II.

Abadal, R. (1972). Pere el Cerimoniós i els inicis de la decadência política de Catalunya. Barcelona: Edicions 62.

Alart, J. (1867). Notes et documents historiques sur le Département des Pyrénées-Orientales. Perpignan: Charles Latrobe.

Alchalabi, F. (2008). A chronicler king: rewriting history and the quest for image in the catalan chronicle of Peter III (1319-1336/1387). Imago Temporis. Medieum Aevum, 2, 177-189.

Arias Bonet, J. A. (1972). Nota sobre el Códice neoyorkino de la Primera Partida. Anuario de Historia del Derecho Español, 42.

Aurell, J. y Serrano-Coll, M. (2014). The Self-Coronation of Peter the Ceremonious (1336): Historical, Liturgical, and Iconographical Representations. Speculum, 89, 66-95.

Authier-Revuz J. (1984). Hétérogénéité(s) énonciative(s). Langages, 19(73), 98-111.

Bacardí, M. (2012). La traducció en la cultura catalana. En Montserrat Bacardí et al. (Dirs.), Teoria i pràctica de la traducció (pp. 181-202). Barcelona: Editorial UOC.

Benito, P. (2004). Fams i caresties a la Mediterrània occidental durant la baixa edat mitjana. El debat sobre 'les crisis de la crisi'. Recerques, 49, 179-194.

Bertran, P. (2005). Les respostes de la baixa noblesa catalana al reclam de Pere el Cerimoniós per anar a Sardenya (1354). En M.T. Ferrer et al. (Dirs.), La Corona Catalanoaragonesa i el seu Entorn Mediterrani a la Baixa Edat Mitjana (pp. 1-22). Barcelona: CSIC.

Bofarull, P. (Ed.) (1850). Colección de documentos inéditos del Archivo de la Corona de Aragón, Archivo de la Corona de Aragón. Barcelona: José Eusebio Monfort, t. VI.

Bohigas, P. (Ed.). (1947). Tractats de Cavalleria. Guillem de Vàroich. De Batalla. Pere III: Tractat de Cavalleria. Pere Joan Ferrer: Sumari de Batalla a Ultrança. Ponç de Menaguerra: Lo Cavaller. Barcelona: Barcino.

Bosch, S. (1936). Les Partides i els textos catalans didàtics sobre cavalleria. Revista d'estudis universitaris catalans, 22, 655-680.

Cabezuelo Pliego, J. V. (2006). Formas feudales en el traspaso de la posesión de fortalezas 'ad consuetudinem yspanie'. En J. V. Cabezuelo Pliego (Dir.), Alcaidias y fortalezas en la España medieval (pp. 155-191). Alcoy: Marfil.

Cano Aguilar, R. (1989). Los prólogos alfonsíes. Cahiers de linguistique hispanique médiévale, 14-15, 79-90.

Cano Aguilar, R. (1996). La ilación sintáctica en el discurso alfonsí. Cabiers de Linguistique médiévale, 21, 295-324.

Cawsey, S. (2002). L'eloqüència reial i la Corona d'Aragó, c. 1200-1450. València: Universitat de València.

Cingolani, S. M. (1990-91). Nos en leyr trovemos plazer e recreation. L'estudi sobre la difusió de la literatura d'entreteniment a Catalunya els segles XIV i XV. Llengua \& Literatura, 4, 39-127.

Cingolani, S. M. (2009). Nel Taller storiografico di Santa Maria di Ripoll. En S. Marinetti (Dir.), Filologia aperta ovvero per amicizia. Scritti offerti a Fabrizio Beggiato,(pp. 71-90). Perugia: Pliniana.

Cingolani, S. M. (2011). Del monasterio a la cancillería. Construcción y propagación de la memoria dinástica en la Corona de Aragón. En P. Martínez Sopena y A. Rodríguez (Dirs.), La construcción medieval de la memoria regia (pp. 365-387). Valencia: Universitat de València.

Cingolani, S. M. (2019). Relato, oratoria y discurso: el pasado como instrumento de comprensión y control en tiempo del rey Pedro Tercero. En F. Bautista, C. Laliena y G. Tomás (Dirs.), Cultura y poder del Estado en la Corona de Aragón. Historiadores e historiografía en los siglos XIII-XVI (pp. 15-38). Zaragoza: Prensas de la Universidad de Zaragoza.

Conde y Delgado de Molina, R. (Ed.). (2008). Reyes y Archivos en la Corona de Aragón: siete siglos de reglamentación y práxis archivistica (siglos XII-XIX). Zaragoza: Institución "Fernando el Católico" (Fuentes Históricas Aragonesas, 44). 
Craddock, J. (1974). La nota cronológica inserta en el prólogo de las Siete Partidas. Edición y comentario. Al Andalus, $39,363-390$

Craddock, J. (1981). La cronología de las obras legislativas de Alfonso X el Sabio. Anuario de Historia del Derecho Español, 51, 365-418.

Craddock, J. (1983). Must the King Obey his Laws? En Geary (Ed.), Florilegium Hispanicum: Medieval and Golden Age Studies Presented to Dorothy Clotelle Clarke (pp. 71-79).Madison: Hispanic Seminary of Medieval Studies.

Craddock, J. (1986a). El Setenario: última e inconclusa refundición alfonsina de la primera Partida. Anuario de Historia del Derecho Español, 56, 441-466.

Cradock, J. (1986b). The Legislative Works of Alfonso X, el Sabio. A critical bibliography. London: Grant \& Cutler.

Craddock, J. (1992). Los pecados veniales en las Partidas y en el Setenario: dos versiones de Graciano, Decretum D. 25c. 3. Glossae, 3, 103-116.

d'Arienzo, L. (1981). La cancelleria di Pietro IV d'Aragona nell'assedio di Alghero del 1354. Archivio Storico Sardo, 32, 139-157.

Díaz de Montalvo, A. (Ed.) (1491). Siete Partidas. Sevilla: Ungut \& Polono.

Elías de Tejada, F. (1963). El pensamento politico catalán (987-1479). Sevilla: Ediciones Montejurra, t. I.

Elvira, J. (1996). La organización del párrafo alfonsí. Cabiers d'Études Hispaniques Médiévales, 21, 325-342.

Ensenyat Pujol, G. (2018). La filosofía discursiva de Pedro el Cerimonioso respecto a la reintegración de la corona de Mallorca a la corona de Aragón. Medievalista, 23, 1-26.

Estepa Díez, C. (1984). Alfonso X y el 'fecho del Imperio'. Revista de Occidente, 43, 43-54.

Estrada-Rius, A. (2017). El jurista y el poder público en la Cataluña Medieval. En J.M. Pérez y T. Montagut (Dirs.), Los juristas catalanes y el Estado español (pp. 39-77). Madrid: Marcial Pons.

Ferran Planas, E. (2006). El jurista Pere Albert i les Commemoracions. Barcelona: Institut d'Estudis Catalans.

Ferrando, A. (2013). La llengua cancelleresca a la Corona d'Aragó. En M. Rodrigo Lizondo (Dir.). Corpus documental de la Cancelleria de la Corona d'Aragó (1291-1420). Textos en llengua catalana (pp. 13-52). Valencia: Publicacions de la Universitat de València (Fonts Històriques Valencianes, 56A).

Ferrer, M. (1970-71). El patrimoni reial i la recuperació dels senyorius jurisdiccionals en els estats catalano-aragonesos a la fi del segle XIV. Anuario de Estudios Medievales, 7, 357-370.

Ferrer, M. (1988). La tinença a costum d'Espanya en els Castells de la frontera meridional valenciana (segle XIV). Miscellània de Textos Medievals, 4, 1-102.

Ferrer, M. (2001). La organización militar en Cataluña en la Edad Media. Revista de Historia Militar, 1, 119-222.

Finke, H. (Ed.). (1908). Acta aragonensia. Berlin: Neudruck der Ausg., t. I.

Garcia Edo, V. (Ed.). (2010). El Llibre Verd Major de Perpinyà (segle XII-1395). Barcelona: Fundació Noguera.

García Gallo, A. (1951-52). El 'Libro de las Leyes' de Alfonso el Sabio. Del Espéculo a las Partidas. Anuario de Historia del Derecho Español, 21-22, 345-528.

García Gallo, A. (1976). Nuevas observaciones sobre la obra legislativa de Alfonso X. Anuario de Historia del Derecho Español, 46, 609-670.

García y García, A. (1963). Un nuevo códice de la Primera Partida de Alfonso X el Sabio. Anuario de Historia del Derecho Español, 33, 267-343.

Genette, G. (1982). Palimpsestes: La littérature au second degré. París: Seuil.

Genette, G. (1987). Seuils. París: Seuil.

Gimeno, F. (2007). Entre el autor y el lector: producir libros manuscritos en catalán (siglos XII-XV). Anuario de Estudios Medievales, 37(1), 305-366.

Gimeno, F. (2009). Estudi introductori. En Ordinacions de la Casa i Cort de Pere el Cerimoniós. 13-48.

Gimeno, F. y Gonzalbo, D. y Trenchs, J. (2009). Ordinacions de la Casa i Cort de Pere el Cerimoniós. Valencia: Edicions Universitat de València (Fonts Històriques Valencianes, 39). 
Gomes, Rita C. (2003). The Making of a Court Society: Kings and Nobles in Late Medieval Portugal. Cambridge: Cambridge University Press.

Gómez Redondo, F. (1998). Historia de la prosa medieval castellana, 3 t. 1 (La creación del discurso prosistico: el entramado cortesano). Madrid: Cátedra.

Hillgarth, J. N. (1992-1993). La personalitat política de Pere III a través de la seva Crònica. Llengua i Literatura, 5 , 7-102.

Iglesia Ferreirós, A. (1986). Fuero Real y Espéculo. Anuario de Historia del Derecho Español, 52. 111-191.

Iglesia Ferreirós, A. (1987). Una traducción catalana de la segunda Partida. Anuario de Estudios Medievales, 17, 265-278.

Iglesia Ferreirós, A. (2005). Constituere consuetudines et condere legem. Initium, 10, 3-84.

Kantorowicz, E. (1957). The King's Two Bodies. A Study in Mediaeval Political Theology. Princeton: Princeton University Press.

Lacomba, M. (2004). Un discours historique marqué par la causalité: l'utilisation de la conjonction ca dans l'Estoria de España d'Alphonse X. Cahiers d'Études Hispaniques Médiévales \& Annexes, 27, 71-82.

Lainé, F. (2009). Des Leges Palatine aux Ordinacions de Pierre IV, un modèle dérobé. En Constitution, circulation et dépassement de modèles politiques et culturels en péninsule Ibérique (pp. 17-55). Bordeaux: Presses Universitaires de Bordeaux.

Las Siete Partidas del rey don Alfonso el Sabio, cotejadas con varios códices antiguos. Madrid: Imprenta Real, 1807 [edición de la Real Academia de la Historia].

LBL - MS Add. 20.787, British Library, Londres.

Lodares, J. R. (1996). El mundo en palabras. Sobre las motivaciones del escritorio alfonsí en la definición, etimología, glosa e interpretación de voces. Cabiers de Linguistique Hispanique Médiévale, 21, 105-118.

López, G. (Ed.) (1555). Las Siete Partidas del sabio rey don Alfonso el nono. Nuevamente glosadas por el licenciado Gregorio Lopez del Consejo Real de Indias de su Majestad. Salamanca [edición de Gregorio López en reproducción anastática del Boletín Oficial de Estado, 1974]

Martin, G. (2001). Datation du Septénaire: rappels et nouvelles considérations. Cabiers de Linguistique Hispanique Médiévale, 24, 325-342.

Martin, G. (2006). De nuevo sobre la fecha del Setenario. e-Spania, 2. Recuperado de http://journals.openedition.o $\mathrm{rg} / \mathrm{e}-\mathrm{spania} / 381$

Martin, G. (2010). Le concept de 'Naturalite' dans les Sept Parties d'Alphonse X le Sage. En Jara Fuentes, J.A, M. Georges e I. Alfonso Antón (Eds.). Construir la identidad en la Edad Media. Poder y memoria en la Castilla de los siglos VII a XV (pp. 145-163). Cuenca: Ediciones de la Universidad de Castilla - La Mancha.

MN0 - MS Vitr. 4-6, Biblioteca Nacional de España

MN6 - MS 12793 Biblioteca Nacional de España

Montagut, T. (1995). Presencia de Las Partidas en el derecho catalán. En Alvarado Planas (Dir.), Espacios y fueros en Castilla-La Mancha (siglos XI-XV): una perspectiva metodológica (pp. 487-505). Madrid: Ediciones Polifemo.

Mutgé, J. (2001). L'abastament de blat a la ciutat de Barcelona en temps d'Alfons el Benigne (1327-1336). Anuario de Estudios Medievales, 31, 649-660.

O'Callaghan, J. (1983). Sobre la promulgación del Espéculo y del Fuero Real. En Carlé, Grassotti y Orduna (Eds.), Estudios en homenaje a Don Claudio Sánchez Albornoz en sus 90 años (pp. 167-180). Buenos Aires: Instituto de Historia de España.

Ordenamiento de Alcalá MS Vitr. 15-7 Biblioteca Nacional de España.

Palacios Martín, B. (1944). El manuscrito de San Miguel de los Reyes de las 'Ordinacions' de Pedro IV. Estudio. Valencia: Scriptorium S.L. - Ediciones Limitadas, vol. I.

Panateri, D. (2013). La tortura judicial en las Siete Partidas de Alfonso X, el Sabio (un análisis sobre el prólogo al trigésimo título de la Partida VII). En Rodríguez (Ed.), Palimpsestos. Escrituras y reescrituras de las culturas antigua y medieval (pp. 267-277). Bahía Blanca: UNS. 
Panateri, D. (2015). Naturaleza y monarquía, la identidad en la Edad Media castellana. En Aladazábal (Comp.), Territorios, Memoria e Identidades (pp. 267-278). Buenos Aires: Consejo Nacional de Investigaciones Científicas y Técnicas.

Panateri, D. (2017a). El discurso jurídico alfonsí y sus implicancias políticas. Madrid: Dykinson.

Panateri, D. (2017b). La política en el discurso jurídico alfonsí. Una interpretación a partir de sus variantes textuales. Cuadernos de Historia del Derecho, 24, 187-202.

Panateri, D. (2018). Sapiencialismo y legalismo, una distinción útil para las Siete Partidas. 7PartidasDigital. Edición crítica digital de las «Siete Partidas». Recuperado de https://7partidas.hypotheses.org/1170.

Panateri, D. (2021). ¿Qual deve ser el rey en sus palabras? Algunas precisiones sobre las Siete Partidas y su tradición manuscrita". En J. M. Fradejas Rueda, R. Pichel y E. Jerez Cabrero (Eds.), Las "Siete Partidas" del Rey Sabio. Una aproximación desde la filología digital y material. Madrid / Frankfurt am Main: Iberoamericana / Vervuert.

Péquignot, S. (2002). Enregistrer, ordonner et contrôler: les documents diplomatiques dans les Registra Secreta de Jacques II d'Aragon. Anuario de Estudios Medievales, 32(1), 431-479.

Pérez Martín, A. (1992). La obra legislativa alfonsina y puesto que en ella ocupan las Siete Partidas. Glossae. Revista de Historia del Derecho Europeo, 3, 9-63.

Pichel, Ricardo (2018). El códice neoyorquino de la Primera Partida (HSA, HC397/573). Notas para su actualización cronológica y geográfica. 7PartidasDigital, 2, 1-17.

Pichel, Ricardo (2021). En torno al contexto de producción del códice neoyorquino de la Primera Partida (HSA, HC397/573). Olivar. Revista de literatura y cultura españolas, 21(34).

Puigdengolas, J. (2021).Lector in ffabla. Estructuras del Setenario de Alfonso X el Sabio (I). Olivar. Revista de literatura $y$ cultura españolas, 21(34).

Rodríguez Velasco, J. (2006). Theorizing the Language of Law. Diacritics, 36(3/4), 64-86.

Rodríguez Velasco, J. (2010). La urgente presencia de Las Siete Partidas. La Corónica, 38(2), 97-134.

Rubió Lluch, A. (1908-1921). Documentsper l'història de la Cultura Catalana Mig-eval. Barcelona: Institut d'Estudis Catalans, vols. I-II.

Sabaté, F. (2006). La tenencia de castillos en la Cataluña medieval. En J. V. Cabezuelo Pliego (Dir.), Alcaidías y fortalezas en la España medieval (pp. 69-136). Alcoy: Marfil.

Sabaté, F. (2009). Oligarchies and Social Fractures in the Cities of Late Medieval Catalonia. En Asenjo-Gozález (Dir.), Oligarchy and Patronage in Late Medieval Spanish Urban Society. Studies in European Urban History (pp. 1-15). Turnhout: Brepols.

Sabaté, F. (2016). L'abus de pouvoir dans la Couronne d'Aragon (XIIIe-XIVe siècle): corruption, stratégie ou modèle? En Gilli (Dir.), La pathologie du pouvoir: vices, crimes et délits des gouvernants (pp. 293-328). Leiden: Brill.

Sabaté, G. y Soriano, L. (2015). La cavalleria a la Corona d'Aragó: tractats teòrico-jurídics de producció pròpia. eHumanista, 31, 154-170.

Sánchez-Prieto Borja, P. (1998). Cómo editar los textos medievales. Criterios para su presentación gráfica. Madrid: Arco Libros.

Sevillano Colom, F. (1950). Apuntes para el estudio de la cancillería de Pedro IV el Ceremonioso. Anuario de Historia del Derecho Español, 20, 137-241.

Sevillano Colom, F. (1970). Mateu Adrià, protonotario de Pedro IV. En VIII Congreso de Historia de la Corona de Aragón (pp. 103-118). Valencia, t. II, vol. II.

Tarrant, R. (1987). Toward a Typology of Interpolation in Latin Poetry. Transactions of the American Philological Association, 117, 281-298.

Tasis, R. ([1957] 1994). Pere el Cerimoniós i els seus Fills. Barcelona: Vicens Vives.

Tomás, G. (2020). El Aragonés Medieval: Lengua y Estado en el reino de Aragón. Zaragoza: Prensas de la Universidad de Zaragoza.

Tostes, R. (2020). Do 'seny i bon juhi' na criação do direito público: a mutação do costume na Catalunha Medieval (séculos XII-XIII). Signum, 21(1), 86-112. 
Trenchs Odena, J. y Aragó Cabañas, A. (Eds.). (1983). Las cancillerías de la Corona de Aragón y Mallorca desde Jaime I a la muerte de Juan II. Zaragoza: Instución "Fernando el Católico" (Folia Parisiensia, 1).

Vanderford, K. (Ed.) (1945). Setenario. Buenos Aires: Instituto de Filología, FFyL de la Universidad de Buenos Aires.

Verrié, F. (1989). La política artística de Pere el Cerimoniós. En Perel el Cerimoniós i la seva època (pp. 177-192). Barcelona: CSIC-Institució Milà i Fontanals.

Zoppi Fontana, M. (2007). En las márgenes del texto, intervalos de sentidos en movimiento. Páginas de Guarda, 1(4), 11-39.

\section{Notas}

1. También referiremos al testimonio como HS1 siguiendo la nomenclatura actual propuesta por Siete Partidas Digital (h ttps://7partidas.hypotheses.org/testimonios).

2. https://7partidas.hypotheses.org/

3. En torno a estas cuestiones, cruciales para trabajar con Siete Partidas y evitar el uso de ediciones poco confiable: García Gallo (1951-52), Craddock (1981), Pérez Martín (1992), O’Callaghan (1983), Iglesia Ferreirós (1986), entre otros.

4. Dejamos de lado la edición de la RAH, pues responde a usos e interrogantes distintos.

5. Uso el de Pedro I por no conservarse la de Alfonso. El ms. es el Vitr. 15-7 guardado en la BNE.

6. No es el lugar para desarrollar esta información. Baste citar Estepa Díez (1984) como referencia de dicho suceso histórico de vital importancia en la historia alfonsí.

7. El trabajo de Craddock (1974) y, fundamentalmente, (1981) establece un debate crucial con varios textos de GarcíaGallo, pero fundamentalmente (1951-52) y (1976). Asimismo, la datación de Setenario provista por Craddock (1986), y a todas luces válida, donde contradecía la clásica fecha que, para no llegar al siglo XIX, se sostenía en el trabajo de Vanderord (1945), editor de Setenario, fue objeto de serias discusiones que incluyó como protagonistas últimos a Martin (2001 y 2006) y Gómez Redondo (1998).

8. Sobre las tendencias, Panateri (2021).

9. Una vez más, utilizo la nomenclatura de Siete Partidas Digital. Los manuscritos referidos son Vitr. 4-6 y el MS 12793, ambos conservados en la BNE.

10. La hipotesis de que Mateu Adrià haya sido el "problable traductor de les Partides" viene anunciada por el Rubió a seguir (1921: II, XXVII).

11. Gracias a la iniciativa del proyecto Traduccions al català medieval fins a 1500 de la Universitat Autònoma de Barcelona se puede consultar un amplio catálogo de esas traducciones y ahora disponible en línea: http://www.translatdb.narpa n.net/.

12. Esta tesis ya ha sido defendida por Finke en el estudio prepatorio de la documentación que él ha editado para el reinado de Jaime II (Finke, 1908, I, XXX-XL). Se puede ver un planteamiento más actual del tema en Antoni Ferrando, (2013, pp. 13-52).

13. El propio Antoni Rubió ha recogido varios ejemplos tomados del comercio epistolar de Pedro IV: así, por ejemplo, en 1343 el soberano dirige sus quejas a Ponç de Copons, abad de Poblet, reclamando un ejemplar del Llibre delsfeits, cuyo original el abad tardó en devolverlo a la biblioteca real: contaba más de un año desde que se había completado la nueva copia de la crónica y el monarca pedía el regreso del ejemplar. El mismo se ve en los sucesivos memorandos emitidos por el rey a sus oficiales quejándose de que, entre febrero y abril de 1357, habían sacado del Archivo Real la copia original de las Leges Palatinae y la traducción oficial de las Ordinacions de la Casa i Cort para consulta privada sin hacerlos regresar: "Si lo trellat del libre de les Ordinacions de casa nostra és fet, aportats-lo-ns per persona certa segurament e bé e que nos puguen afollar per pluja ne per àls, e axí l'original com lo trellat" (ACA, Cancillería real, reg. 1.149, f. 63v; Rubió, 1921, II, p. 124; Gimeno, 2007, p. 332).

14. "En la Cancillería había muchos escribanos, de manament y de registro, como los califican las Ordinacions. Muchos escribanos disponían de una doble competencia gráfica: escribían góticas textuales y al mismo tiempo las cursivas documentales --minúsculas cancillerescas- que utilizaron tanto para escribir las cartas reales como los textos diplomáticos y también los libros derivados de la gestión económica del patrimonio real. La figura de estos escribanos resulta importantísima por lo que respecta a la fortuna del libro registro y, consecuentemente, a la introducción de las escrituras cursivas en el ámbito librario. La presencia de estas cursivas documentales en este ambiente constituye uno de los elementos definitorios del formato de libro designado como registro. Ciertamente, el interés del Ceremonioso por la literatura se remonta al principio de su reinado; fue precisamente gracias a esta participación activa por lo que la Cancillería se convirtió en un centro de producción y copia de libros manuscritos. Ésta, utilizando sus infraestructuras y personal, y siguiendo el modelo y comportamiento de los scriptoria monásticos, dedicó a algunos de sus copistas 
profesionales a producir y copiar libros. (...) Ilustrativa resulta la carta que dirigió el rey desde Barcelona a su hijo, el duque de Gerona, el 30 de junio del año 1373. El tenor de la mencionada carta dice así: 'Molt car Primogènit: Com haurets mester libres, que Nós hajam, fets-nos-ho saber e Nós farem-vos-en fer traslats, car ja tenim certs scribans qui-ns fan trellats d'aquells que és necessari. / Dada ut supra. / Rex Petrus. / Dominus rex missit signatam'. Así pues, la Cancillería se convirtió, en ocasiones, en una especie de scriptorium para satisfacer las necesidades bibliográficas del rey y de los miembros de su familia" (Gimeno, 2007, pp. 326-327).

15. En este sentido Cingolani ha identificado una nueva etapa inagurada bajo el mecenazgo del Ceremonioso: "El proceso de estricta vinculación entre la corte y la cancillería, en cuanto lugar de conservación y producción de memoria histórica y modelos de realeza, no se vuelve a reactivar del todo hasta que Pedro IV retoma la iniciativa para llegar a una modelización definitiva -aun así su panteón-biblioteca estará en un monasterio-, con la redacción de la Crónica general y del Libre particular" (Cingolani, 2011, p. 387).

16. Este añadido ha sido hecho por la mano del proprio Mateu Adrià, quien ha alterado la iussio del manuscrito original del 1344 para poner su assinatura, raspando así la rúbrica de Gil Pérez ("Signum E[gidii] P[etri], mandato domini regis qui eam vidit”), lo cual había sido notario régio entre los años 1336-1345 (cfr. Palacios, 1994, p. 55).

17. Como lo ha notado Sevillano, ya en 1344 Adrìa era referido como escribano secretario de la cancellería y en las Cortes de 1350 como escribano y notario público (ACA, C, reg. 876, f. 135-136 ss. - cfr. Sevillano, 1950, p. 145).

18. "Aquesta intervenció no sols es limitaria a la idea del projecte, ans també afectaria la mateixa traducció del text de les Leges, que ell coneix perfectament o si més no compara, com ho proven tot un conjunt de notes autografes que tradueixen textos omesos involuntàriament pels copistes i ell, revisant la traducció, ha descobert. A tall d'exemple servirà la intervenció autògrafa que hom troba al f. 77 [Universitat de València, Biblioteca General i Històrica, ms. 1501], on anota el contingut del començament de la quarta part i primera rúbrica oblidats pels copistes (...) i la del f. 67r, on el rei ha descobert la mancança de la rúbrica del text a l'ofici Dels porters ho sotsporters qui son liurats als hoüdors. Així doncs, el rei presumiblement participarà en el procés de traducció al llarg dels diversos moments pels quals travessà: a) inspirant-lo; b) manant-lo, de bon començament; c) seguint els treballs, i, finalment, d) corregint i esmenant el primer fruit obtingut, com ho palesen el conjunt d'intervencions autògrafes que hom troba tot al llarg del manuscrit original i que ara podem analitzar críticament" (Gimeno, 2009, pp. 35-36).

19. A parte las dos versiones catalanas asignadas al encargo de Mateu Adrià, hay una segunda traducción catalana de Partidas cuya copia parece haber sido realizada a finales del siglo XIV, y que se encuentra actualmente en el ms. 15 de la Biblioteca de Catalunya.

20. Véase también la notación reproducida en el catálogo de Traduccions Catalanes Medievals con la rúbrica siguiente: Alfonso X of Castile (the Wise) Libro de las partidas (1256-65) [TCM 6.1] trans. Mateu Adrià et al., b. 1365; trans. 2 (1383); trans. 3, XIV-XVc.(disponible en línea: https://translat.narpan.net/prolegs/ CONSPECTVSTRANSLATIONVM 2016.pdf).

21. En 1343 Pedro IV transmitía profundas quejas a sus delegados ordinarios en razón de los límites creados a su património tras las enajenaciones y las reducciones impuestas a sus rentas directas (ACA, C, cartas reales, Pedro III [IV], reg. 2556).

22. Donde se lee en el título: Ley XXXII. Com se deuen donas los castells al rey que fossen guanyats en ses conquestes per sos vassalls o per sos naturals (Abadal, 1914, p. 97).

23. “(...) uti et gaudere libere valeatis prout melius et plenius in ceteris locis Cathalonie observantur consuetudine ville Perpiniani qua caveatur, quod Usatici Barchinone non vendicant sibi locum infra dictam villam vel quovis alio usu contrario non obstante, quibus tamen consuetudinibus et usibus ac privilegiis aliis dicte ville in aliquot non intendimus derogare, immo eis uti possitis sicut prius, prout eis hactenus usi estis si vobis expediens videatur" (Garcia Edo ed., 2010, p. 564).

24. Véase también José Vicente Cabezuelo (2006, pp. 155-191), María Teresa Ferrer (2001, pp. 141-144) y las notas publicadas por Alart en el siglo XIX (1867, pp. 33-35).

25. Más tarde republicado y revisto (Abadal, 1970, II, pp. 335-379).

26. Por referir a los términos utilizados por Kantorowicz (1957).

27. Esta idea está simplificada. La explicación puede buscarse en Rodríguez Velasco (2010) y en Panateri (2017a).

28. Con respecto a las manos, Pichel (2021) en este mismo volumen demuestra sustantivamente que son varios y no una como quiso ver García y García en 1963.

29. De algún modo, una vez más, simplificamos a efectos de contribuir a la narrativa en un tema que en esta oportunidad no es central de nuestro trabajo, pero referimos a la idea planteada por Rodríguez Velasco (2006).

30. Sobre la relación entre Naturaleza y poder monárquico en Alfonso X, Martin (2010) y Panateri (2015).

31. En referencia a la relación del texto alfonsí con su glosa, en particular la producida en 1555, puede constatarse esta aserción a través de Panateri (2015). Finalmente, en relación a la denominada sintaxis alfonsí: Elvira (1996), Cano Aguilar (1996), Lacomba (2004) y, concretamente referido a Partidas, Panateri (2017a).

32. Esto es así tanto en García Gallo (1951-52) como en Craddock (1981). Asimismo, Panateri hizo lo propio en 2017 b. 
33. Al respecto, el trabajo de Craddock (1992) echa luz sobre la excepcionalidad de este manuscrito en su análisis sobre los pecados veniales dentro de Partidas y Setenario. Este trabajo, lo que expresa incluso más allá del análisis concreto que lleva adelante, es el primer paso de una serie necesaria para determinar la relación entre Partidas y Setenario, donde el Neoyorkino quizá sea un testimonio a considerar.

34. Quizá esta circunstancia, a todas luces entendible a comienzos de la década de 1963, se deba al estado de conocimiento sobre la tradición. Asimismo, la edición de 1807 gozaba de buena salud entre algunos especialistas. Hoy es insostenible basar un estudio sobre Partidas con esa edición en cualquier instancia previa a ese año.

35. La relación estrecha entre neoyorkino y Setenario fue puesta de relieve someramente por Arias Bonet (1972).

36. En relación al orden interno de Setenario y los distintos "sietes" (micro y macro) que pueden encontrarse a lo largo de esa obra, véase el texto se Puigdengolas en este mismo volumen.

37. Transcribo según Sánchez-Prieto Borja (1998): desarrollo abreviaturas silenciosamente y separo las palabras acorde a su identidad lexicofráfica y gramatical. Normalizo la puntuación, el uso de minúsculas y mayúsculas, la prosodia en todos los casos, la fusión por fonética sintáctica, las grafías según su valor fonético, toda duplicación y el dígrafo qu para su valor fonético cu. El testimonio presenta un uso irregular en las h en general (especialmente en h-omne y h-onra[do]), respeto estas diferencias. Agrego h allí donde un tiempo verbal compuesto puede confundirse con una preposición. Finalmente, hago otros agregados cuando se presentase una lectura dificultosa y deba sugerir lectura o por faltar algún componente oracional de modo evidente. En todos los casos, esta intervención la marco entre corchetes.

38. Para esta transcripción utilizo la edición de Vanderford (1945). En tal sentido, respeto sus decisiones editoriales, las cuales comprenden respeto de grafías y duplicaciones, así como intervención sobre la puntuación y prosodia.

39. Ordenamiento de Alcalá, ejemplar de Pedro I, BNE Vitr. 15-7 (2v.b).

40. Sobre esto está trabajando Daniel Panateri, quien espera terminar en breve todo este estudio con edición completa del testimonio aquí presentado. 